\title{
Preparation of mouse anti-human rotavirus VP7 monoclonal antibody and its protective effect on rotavirus infection
}

\author{
MEI ZHA ${ }^{1}$, JING YANG ${ }^{2}$, LINLIN ZHOU ${ }^{1}$, HONGREN WANG $^{1}$, XING PAN $^{3}$, ZHAOMIN DENG $^{4}$, \\ YUAN YANG ${ }^{1}$, WANYI LI ${ }^{1}$, BAONING WANG ${ }^{1}$ and MINGYUAN LI ${ }^{1}$ \\ ${ }^{1}$ Department of Microbiology, West China School of Basic Medical Sciences and Forensic Medicine, Sichuan University, \\ Chengdu, Sichuan 610041; ${ }^{2}$ Institute of Liver Diseases, Renmin Hospital; ${ }^{3}$ Institute of Infection and Immunity, \\ Taihe Hospital, Hubei University of Medicine, Shiyan, Hubei 442000; ${ }^{4}$ Hospital of Chengdu Office of People's \\ Government of Tibetan Autonomous Region, Chengdu, Sichuan 610041, P.R. China
}

Received June 9, 2018; Accepted February 15, 2019

DOI: $10.3892 /$ etm.2019.7708

\begin{abstract}
The aim of the current study was to prepare and identify mouse anti-human rotavirus (RV) VP7 monoclonal antibodies and explore their protective effects on RV infection. The mouse anti-human RV VP7 monoclonal antibody was produced using the ascites method and identified via western blot analysis. In vitro neutralization of mouse anti-human RV VP7 monoclonal antibodies was detected by performing an MTT assay. The TCID ${ }_{50}$ value was calculated to obtain antibody neutralization titers. A mouse RV infection model was generated to assess the protective effect of the mouse anti-human RV VP7 monoclonal antibody in experimental animals. Monoclonal antibodies were successfully prepared and their purity reached $\geq 90 \%$. Western blotting demonstrated that monoclonal antibodies specifically bound to the purified Wa RV strain, with a specific reaction band at $\sim 40 \mathrm{kDa}$. Monoclonal antibody in vitro neutralization results demonstrated that cell survival rate in the virus + monoclonal antibody group was higher than that in virus + maintenance fluid group $(\mathrm{P}<0.05)$. Monoclonal antibody neutralization titer detection revealed that the cytopathic effect did not extend beyond 4 days. In addition, the calculated monoclonal antibody neutralization titer was 1:446. The results revealed that the positive rate of colloidal gold RV in the $100 \mu \mathrm{l}$ monoclonal antibody group was significantly lower than that in the control group $(\mathrm{P}<0.05)$. Furthermore, the protection rate of the $100 \mu \mathrm{l}$ monoclonal antibody group was $71.4 \%$, whereas the $50 \mu \mathrm{l}$ monoclonal antibody group was $42.9 \%$ and the ribavirin group was $57.1 \%$. In conclusion, the results of the current study demonstrated that mouse anti-human RV
\end{abstract}

Correspondence to: Dr Baoning Wang or Professor Mingyuan Li, Department of Microbiology, West China School of Basic Medical Sciences and Forensic Medicine, Sichuan University, No. 17, Section 3, Renmin South Road, Chengdu, Sichuan 610041, P.R. China

E-mail: danial.w@163.com

E-mail:1my3985@sina.com

Key words: mouse, mouse monoclonal antibody, rotavirus, VP7
VP7 monoclonal antibodies can be successfully prepared using ascites method. These antibodies also effectively neutralize the cytotoxic effects of the human RV Wa strain in vitro and mouse anti-human RV VP7 monoclonal antibodies also exhibited a good protective role in mice. Furthermore, greater protective effects were observed at a higher dose and the protective effects of these high dose treatments were superior to that of ribavirin.

\section{Introduction}

Rotavirus (RV) belongs to the reovirus subfamily and is the most important causative agents of viral diarrhea in infants and young children, as well as many young animals worldwide (1). It is also the major causative agent of acute diarrhea in children under 5 years of age, which may lead to mortality in severe cases (2). There is currently no efficient drug for the treatment of $\mathrm{RV}$ infections and vaccines remains the only effective and economical means to prevent and control RV (3). RV-encoded structural proteins primarily consist of VP2, VP6, VP4 and VP7, of which VP4 and VP7 are the major neutralizing antigens (4). VP7 accounts for $30 \%$ of the total viral proteins and mediates the viral shedding and host invasion, which is required for RV maturation (5). A previous study demonstrated that the RV VP7 protein exhibits higher antigenicity and immunogenicity than the VP4 protein (6). Therefore a large number of studies have utilized VP7 as the primary target for engineering RV viral gene subunit vaccines, RV nucleic acid vaccines and therapeutic monoclonal antibodies $(7,8)$. However, the ability to produce a large quantity of mouse anti-human RV VP7 monoclonal antibodies is a key factor that determines its success in clinical applications (9). Currently, in vitro culture methods and in vivo induction methods are used to generate a large quantity of monoclonal antibodies. However, during the process of monoclonal antibody production using in vitro culture methods, the culture medium needs to be replaced several times (once per day) and the antibody yield is low. Proliferation of hybridoma cells in animals can overcome these weaknesses. There are currently two methods of in vivo induction for the mass production of monoclonal antibodies; subcutaneous and intraperitoneal injection into the back of mice. However, in the preparation 
of experimental antibodies, the most commonly used method involves the use of ascites $(10,11)$. To the best of the author's knowledge, no studies published thus far have investigated the mass preparation of mouse anti-human RV VP7 monoclonal antibodies using the ascites method. Therefore, in the present study, the feasibility of preparing mouse anti-human RV VP7 monoclonal antibodies using the ascites method was assessed and the protective effect of mouse anti-human RV VP7 monoclonal antibodies on RV infection were verified. These results may enable the screening antiviral drugs for RV and allow investigation of their mechanisms of action.

\section{Materials and methods}

Materials. Liquid paraffin was purchased from Chengdu Kelong Chemical Co., Ltd. (Chengdu, China). Hybridoma cells were kindly provided by Department of Microbiology, West China School of Basic Medical Sciences and Forensic Medicine, Sichuan University (Chengdu, China). An ultraviolet (UV)-visible spectrophotometer was purchased from Beijing Kaiao Technology Development Co., Ltd. (Beijing, China). Horseradish peroxidase (HRP)-labeled goat anti-mouse IgG was purchased from Jackson ImmunoResearch Laboratories, Inc. (West Grove, PA, USA). Trypsin was purchased from Gibco (Thermo Fisher Scientific, Inc.). The $\mathrm{CO}_{2}$ incubator was purchased from SANYO Electric Co., Ltd. (Osaka, Japan). Dimethylsulfoxide (DMSO) was purchased from Sigma-Aldrich; Merck KGaA (Darmstadt, Germany). MA-104 cells were purchased from China Center For Type Culture (Wuhan, China). Maintenance solution (cat. no. YP02476) was purchased from Shanghai Yuan Mu Biotechnology Co., Ltd. (Shanghai, China).

Animals. A total of 50 female Kunming mice (age, 7 days; weight, $6 \pm 1 \mathrm{~g}$ ) were provided by Chengdu Dashuo Biotechnology Co., Ltd., (Chengdu, China). All mice were housed $20-26^{\circ} \mathrm{C}$, humidity $40-70 \%, 12 \mathrm{~h}$ light- $12 \mathrm{~h}$ dark cycle conditions, feeding full-price nutritious pellet feed, access to safe, clean water. The animal experiments performed in the present study were approved by the Committee on Animal Research and Ethics of West China School of Basic Medical Sciences and Forensic Medicine, Sichuan University. Mice in the current study were euthanized via cervical dislocation.

Preparation of mouse anti-human $R V$ Wa strain VP7 monoclonal antibodies. Each mouse received an intraperitoneal inoculation of $0.5 \mathrm{ml}$ liquid paraffin. Following 7 days, hybridoma cells were diluted in serum-free Eagle's minimum Essential medium (EMEM; cat. no. 77203; Beijing Bitab Biotechnology Co., Ltd., Beijing, China). The diluted hybridoma cells were then injected intraperitoneally at a dosage of $2 \times 10^{6}$ cells $/ 0.2 \mathrm{ml} / \mathrm{cell}$. Following a further 7 days, mouse ascites were monitored daily. Ascites were considered to have developed when significant abdominal swelling was observed and skin tension was palpable.

Purification of VP7 monoclonal antibodies. The collected ascites was subjected to agitation and dialysis with loading buffer (20 mM phosphate buffer; $0.15 \mathrm{M} \mathrm{NaCl}, \mathrm{pH} 7.0$ ), and run at a flow rate of $0.5 \mathrm{ml} / \mathrm{min}$. Following dialysis, protein content was detected by the bicinchoninic acid method. The protein purity was detected using BandScan 5.0 software (Glyko Inc., Novato, CA, USA). VP7 monoclonal antibodies were purified by the ammonium sulfate precipitation method (12). Antibodies were purified using a $1 \mathrm{ml}$ HiTrap $^{\text {TM }}$ Protein A (GE Healthcare, Chicago, IL, USA)-prepacked column. The column was equilibrated with 20 times the column volume of PBS loading buffer. A 20-mg sample was selected and re-loaded manually into the column. Loading buffer (20 times the column volume) was then used to wash any unbound protein remaining on the column. The column was then rinsed with elution buffer $(30 \mathrm{mM}$ imidazole; flow rate, $0.2 \mathrm{ml} / \mathrm{min}$; detection wavelength, $214 \mathrm{~nm}$ ) and the elution peak was collected (sample volume, $9 \mathrm{ml}$ ). A total of $1 \mathrm{M}$ Tris- $\mathrm{HCl}$ buffer $(\mathrm{pH}=7.0)$ was immediately added to the elution peak. The eluted protein was mixed with and dialyzed against 24X $20 \mathrm{mM}$ phosphate buffer column buffer. Protein samples were collected and the protein content was measured using a UV-visible spectrophotometer. Samples were stored at $-20^{\circ} \mathrm{C}$ until required.

Identification of VP7 monoclonal antibodies. VP7 monoclonal antibodies were identified via western blotting. RV viral proteins were purchased from American Type Culture Collection (cat. no. ATCCVR-2018). Following the separation of the RV (20 $\mu \mathrm{g}$ protein/lane) by SDS-PAGE using a 10\% separating gel, sufficient transfer buffer was prepared to fill the transfer tank and polyvinylidene fluoride membranes were prepared. Following transfer of the separated proteins, the membrane was washed in Tris-buffered saline five times in a shaker at $4^{\circ} \mathrm{C}$ for $5 \mathrm{~min}$. The membrane was subsequently blocked with $10 \mathrm{ml}$ blocking solution (0.1 M TBST containing 5\% dried skimmed milk) and either transferred to a shaker for $2 \mathrm{~h}$ at room temperature or incubated overnight at room temperature. The membrane was then incubated with the laboratory-produced VP7 primary monoclonal antibodies $(1: 1,000$ in blocking solution) overnight in a shaker at $4^{\circ} \mathrm{C}$. The following day, the membrane was washed in Tris-Tween-buffer-saline (TTBS) three times for $5 \mathrm{~min}$ each. The membrane was subsequently incubated with HRP-labeled goat anti-mouse IgG secondary antibodies (cat. no. 115-035-003; 1:8,000) on a shaker at $4^{\circ} \mathrm{C}$ for $1 \mathrm{~h}$. The secondary antibodies were recovered and the membrane was washed with TTBS three times for 5 min each time. The membrane was then stained with tetramethylbenzidine (cat. no. 54827-17-7; China Chengdu Huaxia Chemical Reagent Co., Ltd.) and the results were recorded by direct photography.

In vitro detection of VP7 monoclonal antibody neutralization. MA-104 cells were digested with $0.25 \%$ trypsin and centrifuged at $447.2 \mathrm{x} \mathrm{g}$ for $3 \mathrm{~min}$ at $4^{\circ} \mathrm{C}$. The supernatant was discarded and the precipitate was resuspended in $1 \mathrm{ml}$ serum-free EMEM. Cells were counted using an optical microscope at a magnification of $\mathrm{x} 100$ and the concentration was adjusted to $2.5 \times 10^{5}$ cells $/ \mathrm{ml}$. Cells $(200 \mu \mathrm{l})$ were transferred to each well and incubated in a $5 \% \mathrm{CO}_{2}$ incubator at $37^{\circ} \mathrm{C}$ for $24 \mathrm{~h}$. The following day, RV viral solution was diluted 10 times and the laboratory-produced VP7 monoclonal antibodies were added to the diluted RV solution at a ratio of 1:10. A negative control with maintenance solution (1:10 in RV) was prepared simultaneously. Following mixing, samples were incubated at $37^{\circ} \mathrm{C}$ for $60 \mathrm{~min}$. The supernatant was discarded before the 
samples were added to a 96-well plate containing the MA-104 cells. The cells were washed with serum-free EMEM three times. A total of $200 \mu \mathrm{l} /$ well of the solution was added to the experimental and the negative control groups. A normal control without virus solution was also included. Each group consisted of 6 parallel wells. The plates were incubated in a $5 \% \mathrm{CO}_{2}$ incubator for $2 \mathrm{~h}$ at $37^{\circ} \mathrm{C}$. The medium was then discarded and $200 \mu \mathrm{l}$ maintenance solution was added to each well. Following incubation at $37^{\circ} \mathrm{C}$ for 3 days, the medium was discarded. To each well, $100 \mu \mathrm{l}$ serum-free EMEM and $20 \mu \mathrm{l}$ MTT was added and the plates were incubated at $37^{\circ} \mathrm{C}$ for a further $4 \mathrm{~h}$. The culture medium was carefully removed and $150 \mu \mathrm{l}$ DMSO was added to each well. Samples were mixed thoroughly in order to completely dissolve the purple precipitate. The optical density (OD) value of each well was detected at $578 \mathrm{~nm}$. Cell survival was calculated using the following formula: Cell survival rate $(\%)=(\mathrm{OD}$ value of test wells $/ O D$ value of control wells) x100\%.

Determination of the neutralization titer of the mouse anti-human RV Wa strain VP7 antibody. MA-104 cells were digested with $0.25 \%$ trypsin and centrifuged at $447.2 \mathrm{x}$ g for $3 \mathrm{~min}$ at $4^{\circ} \mathrm{C}$. The precipitate was then resuspended in $1 \mathrm{ml}$ serum-free EMEM and the cells were counted with an optical microscope at a magnification of $x 100$. The cell concentration was adjusted to $2.5 \times 10^{5}$ cells $/ \mathrm{ml}$. A total of $200 \mu \mathrm{l}$ cell sample was transferred into each well of a culture plate and the cells were cultured in a $5 \% \mathrm{CO}_{2}$ incubator at $37^{\circ} \mathrm{C}$. The following day, RV was diluted 10 times and combined with mouse anti-VP7 monoclonal antibodies at ratios of 1:10, 1:20, 1:40, 1:80, 1:160, 1:320, 1:640 and 1:1,280. A negative control (maintenance solution; $\mathrm{RV}=1: 10$ ) was prepared simultaneously. Following mixing, samples were incubated at $37^{\circ} \mathrm{C}$ for $60 \mathrm{~min}$ before the medium was discarded and the cells were washed with serum-free EMEM three times. A total of $200 \mu \mathrm{l} /$ well of samples in the experimental and the negative control groups were transferred to a fresh 96 -well plate. A normal control consisting of maintenance solution without virus and the antibodies were prepared simultaneously. Each group consisted of six parallel wells. Cells were incubated in a $5 \% \mathrm{CO}_{2}$ incubator for 3 days at $37^{\circ} \mathrm{C}$. The cytopathic effect was monitored daily and the number of lesions were recorded in order to calculate the antibody neutralization titer using the Reed-Muench formula, namely, rotavirus TCID $_{50}=10^{-6.59} / 0.2 \mathrm{ml}$. Briefly, $\mathrm{TCID}_{50} / 0.2 \mathrm{ml}=[\log$ of virus dilution with lesion rate $>50 \%+\log$ of the dilution coefficient $\mathrm{x}$ (lesion percentage $>50-50 \%)] /($ lesion percentage $>50-<50 \%$ ).

Analysis of the protective effects of VP7 monoclonal antibodies in vivo. A RV challenge test was carried out using $500 \mu \mathrm{l}$ 10-6.59 $\mathrm{TCID}_{50} / \mathrm{ml} \mathrm{RV}$. Briefly, all experimental mice were first divided into 3 groups ( $\mathrm{n}=6 /$ group). Mice in two experimental groups were subjected to intragastric administration of $500 \mu 1$ RV solution and RV solution diluted 10 times, respectively. Mice in the control group were administered $500 \mu$ l normal saline. Alterations in body weight were recorded daily after the virus challenge test and this was used as a basis for establishing a model of RV infection in young mice.

In order to establish this model, the 32 Kunming mice were randomly divided into 4 groups $(\mathrm{n}=8 /$ group): Two experimental groups, one positive control group and one negative control group. Intragastric administration at $\mathrm{TCID}_{50}=10^{-6.59}$ (twice daily, every other day) was performed using $200 \mu \mathrm{l}$ RV solution for each mouse. The mental state, including response to the external environment, activity sensitivity, respiratory status and somnolence state in mice was observed by perusal. The body weights of mice were measured by using scales. The RV antigen in mouse feces was detected by the colloidal gold method (13). Following the establishment of the RV infection model (at 6 days following the final infection), the four groups were administered with different treatments three times/day for a period of 6 days, as presented in Table I (2). Mice in the negative control group were treated with $100 \mu 1$ normal saline, $60 \mu \mathrm{g}$ ribavirin (approval no. Chinese Medicine Standard H19999411; China Meheco Topfond Pharma Co., Ltd., Zhumadian, China) was administered to mice in the positive control group and mice in the monoclonal antibody groups were treated with 100 or $50 \mu \mathrm{l}$ monoclonal antibody solutions.

At 6 days following final treatment, mice were sacrificed, dissected and the caecum feces were used to detect RV using immune colloid gold (cat. no. IM4101053; Sichuan Mike Biotechnology Co., Ltd., Chengdu, China) following the manufacturing protocol. Finally, the results of immune colloid gold $\mathrm{RV}$ detection of each group were statistically analyzed and the protective effect of mouse-anti VP7 monoclonal antibodies on RV infection was measured. The following formulae were used: Positive rate of colloidal gold RV detection $(\%)=$ mice with positive colloidal gold RV detection in each group/number of surviving mice in each group $\times 100 \%$ and; protection rate $(\%)=($ positive rate of colloidal gold $\mathrm{RV}$ detection in control group-positive rate of colloidal gold RV detection in treatment group)/positive rate of colloidal gold RV detection in control group x100\%.

Statistical analysis. SPSS 21.0 statistical software (IBM Corp., Armonk, NY USA) was used for statistical analysis. A Fisher's exact test was used to compare mice rotavirus antigen test results following intragastric administration of different preparations. One-way analysis of variance was used to compare the neutralization test results in mice administered with anti-human rotavirus Wa strain VP7 antibodies, with a Dunn-Bonferroni test for post-hoc comparisons. $\mathrm{P}<0.05$ was considered to indicate a statistically significant difference.

\section{Results}

Purification of VP7 monoclonal antibodies. The dialysis and affinity chromatography results were obtained prior to antibody purity detection by SDS-PAGE electrophoresis. The results showed that the protein purity was $>90 \%$ (Fig. 1).

VP7 monoclonal antibody identification. The results of western blot analysis demonstrated that the VP7 monoclonal antibody specifically bound to the purified human RV Wa strain and formed a specific reaction band at a molecular weight of $\sim 40 \mathrm{kD}$ (Fig. 2).

Mouse anti-human RV VP7 monoclonal antibody in vitro neutralization test results. The in vitro neutralization effect of mouse anti-human RV VP7 monoclonal antibodies was detected using an MTT assay. The survival rate of cells in 
Table I. Dosages for different preparation-treated groups.

\section{Group}

Negative control

Positive control

High dose monoclonal antibody

Low dose monoclonal antibody
Preparation and dose

Normal saline, $100 \mu 1 /$ mouse

Ribavirin, $60 \mu \mathrm{g} / \mathrm{mouse}$

Mouse anti-RV-VP7 monoclonal antibody, $100 \mu \mathrm{l} /$ mouse

Mouse anti-RV-VP7 monoclonal antibody, $50 \mu 1 /$ mouse

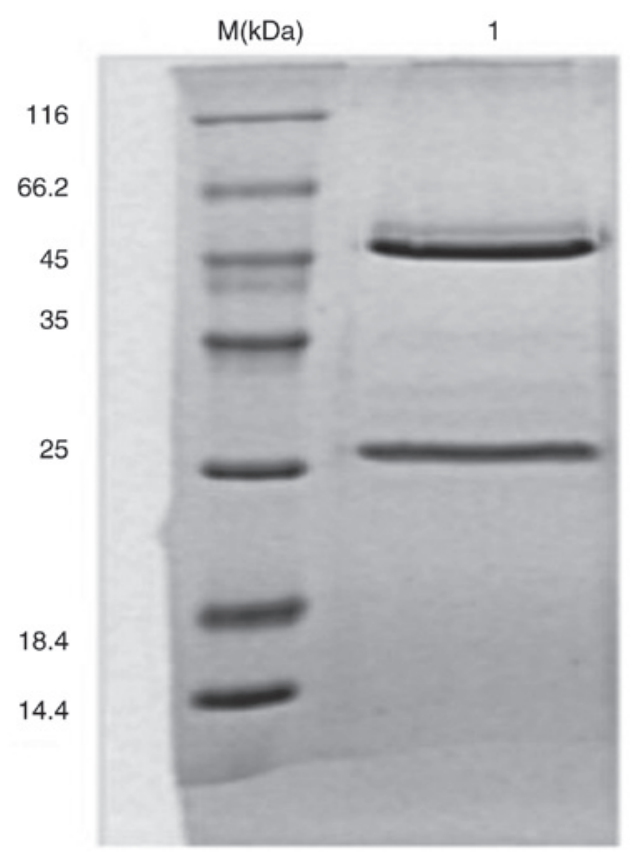

Figure 1. VP7 monoclonal antibody electrophoresis following purification. Mouse anti-human rotavirus IgG was detected. M, protein marker; 1, mouse anti-human rotavirus $\mathrm{IgG}$ (purity $>90 \%$ ).

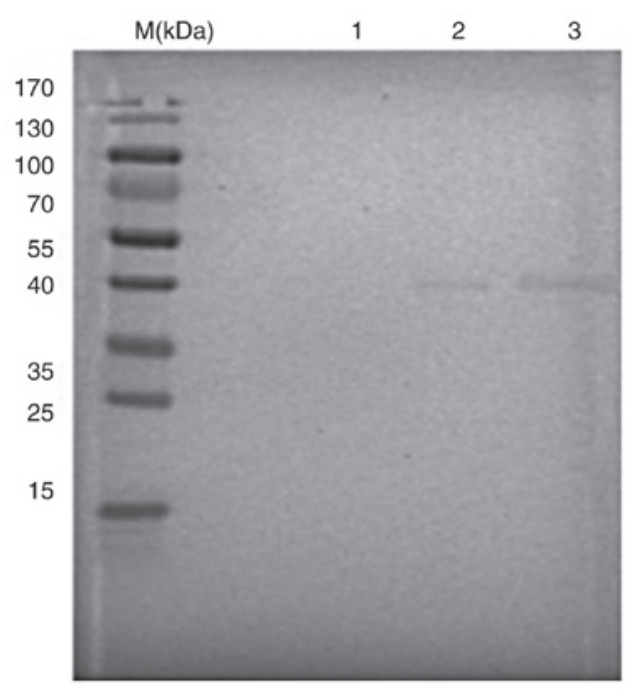

Figure 2. Western blotting identified human rotavirus Wa strain VP7 protein. M, protein marker; 1, MA-104 total cellular protein (negative control); 2, RV (positive control); 3, lab-amplified RV. RV, rotavirus.

the virus plus monoclonal antibody group was $102.1 \%$ (data not shown). By contrast, the survival rate of cells in the virus

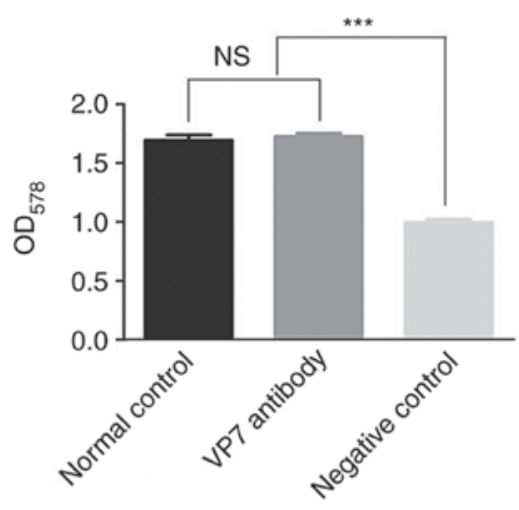

Figure 3. Neutralization test result of mouse anti-human rotavirus Wa strain VP7 antibody. ${ }^{* * *} \mathrm{P}<0.001$.

plus maintenance fluid group was $58.8 \%$ (data not shown). Therefore, the mouse anti-human RV VP7 monoclonal antibody secreted by the hybridoma cells exhibited neutralizing activity (data not shown). The survival rate of cells in the VP7 antibody group was higher than that of cells in the negative control group $(\mathrm{P}<0.05)$, but was similar to that of the normal control group (Fig. 3). By subtracting the survival rate of cells in the virus plus monoclonal antibody group from that of the virus plus maintenance fluid group, it demonstrated that the cell protection rate of monoclonal antibody reached $43.3 \%$.

VP7 monoclonal antibody neutralization titer test results. The MA-104 cell line was infected with mouse anti-human RV VP7 monoclonal antibodies following gradient dilution and its action against human RV was measured. A control group of cells treated with maintenance liquid plus human RV and a normal control group of cells treated with maintenance fluid without virus or antibodies were also included. The number of lesions were observed and recorded each day (7 days were observed). Further lesions did not develop following 4 days. The TCID $_{50}$ was calculated according to the Reed-Muench formula. An antibody neutralization titer of 1:446 was obtained, namely, 1:446 antibody protect $50 \%$ of cells against lesions (data not shown).

$R V$ immune colloidal gold detection in mouse feces at 6 days following intragastric administration of different preparations. In the control group, 8 mice infected with RV were treated with sterile normal saline. Of these, 7 mice exhibited positive immune colloidal gold detection in their feces, with a positive rate of $87.5 \%$. In mice treated with ribavirin, 3 were infected with $\mathrm{RV}$, equating to a positive rate of $37.5 \%$. Of the 
Table II. Mice rotavirus antigen test results following the intragastric administration of different preparations.

\begin{tabular}{lcc}
\hline Group & $\begin{array}{c}\text { Number } \\
\text { of positive } \\
\text { mice }\end{array}$ & $\begin{array}{c}\text { Number } \\
\text { of negative } \\
\text { mice }\end{array}$ \\
\hline Monoclonal antibody $(100 \mu 1)$ group $^{\mathrm{a}}$ & 2 & 6 \\
Monoclonal antibody $(50 \mu 1)$ group $^{\text {Ribavirin group }}$ & 4 & 4 \\
Negative control group & 3 & 5 \\
\hline
\end{tabular}

${ }^{a} \mathrm{P}<0.05$ vs. the negative control group.

mice treated with 100 and $50 \mu 1$ monoclonal antibodies, 2 and 4 mice were infected with $\mathrm{RV}$, with positive rates of 25 and $50 \%$, respectively (Table II).

Further statistical analysis was performed to compare RV infection in different groups treated with different preparations. The results revealed that the positive rate of colloidal gold RV detection in the group treated with $100 \mu 1$ monoclonal antibody was significantly lower than that of the control group $(\mathrm{P}<0.05)$. The remaining experimental groups demonstrated no significant differences when compared with the control group.

Using the aforementioned formula, the protection rate of $\mathrm{RV}$-infected mice treated with different preparations were as follows: Ribavirin positive control group, 57.1\%; $100 \mu 1$ monoclonal antibody group, $71.4 \%$ and $50 \mu \mathrm{l}$ monoclonal antibody group, $42.9 \%$.

\section{Discussion}

Kunming mice are the most productive and abundant outbred mice in China, which originate from Swiss mice (14). Kunming mice also exhibit strong disease resistance, adaptability, a high reproductive rate, a high survival rate and are relatively cheap to purchase (15). These mice also represent $\sim 70 \%$ of total mice used in biomedical experiments, involving pharmacology, toxicology and the production and verification of drugs and biological products in China (16). In the present study, a large number of monoclonal antibodies were prepared using the ascites method in Kunming mice. When using ascites to prepare monoclonal antibodies in large quantities, paraffin oil must be injected into the abdominal cavity (17). This is to promote immunosuppression, preventing immune rejection reactions and accelerating tumor growth (18). This step can also induce mice to concentrate monocytes and lymphocytes in the peritoneal cavity, avoiding the development of solid tumors and increasing the production of ascites in mice $(19,20)$. The number of injected hybridoma cells may also affect the preparation of monoclonal antibodies using ascites and may lead to cell death if it is excessive, or a lack of ascites production if the number is too low (21). Generally, $10^{5}-10^{6}$ hybridoma cells are appropriate (22). In addition, fewer injections of hybridoma cells may lead to increased tolerance and survival rates, delayed pathological alterations and reduced pain in mice (23). By inoculating $2 \times 10^{6}$ cells $/ 0.2 \mathrm{ml}$ into the peritoneal cavity of mice, a large number of ascites were successfully harvested in the present study.

Antibodies prepared using the ascites method are mixed with a large number of contaminating proteins, including lipid proteins, transferrin, macroglobulin, albumin and serum, which do not meet the requirements for structural and functional studies $(24,25)$. Therefore, antibody purification is required (26). The principle of antibody purification is based on unique charge characteristics, hydrophobicity, chelation with metal ions, specificity, affinity, solubility and molecular size $(27,28)$. In the present study, the ammonium sulfate precipitation method was employed. Due to differences in the hydrophobicity of different proteins, altering the salt concentration allows for protein precipitation. The RV VP7 monoclonal antibody precipitates in ammonium sulfate with a concentration range of 30-50\%, which allows for the removal of contaminating proteins $(29,30)$. This purification method stabilizes the antibody, reduces the risk of antibody activity loss, removes the majority of contaminating proteins and concentrates the sample (31). However, a disadvantage of this method is that some antibody activity is lost following precipitation or co-precipitation with other contaminating proteins, which may affect the antibody purity (32). Therefore, following purification, antibody purity must be determined (33). In the present study, the results revealed that the antibody purity was $90 \%$. Therefore, the experimental requirements were met. Further detection of antibody specificity by western blot analysis revealed that the monoclonal antibody exhibited a specific reaction band at $\sim 40 \mathrm{kDa}$, indicating that it bound to the purified human RV Wa strain.

The MTT colorimetric method is used to detect the activity and growth rate of cells. The OD value was measured in the current study using a spectrophotometer at $578 \mathrm{~nm}$ to determine the number of surviving cells following an MTT assay $(34,35)$. The results demonstrated that the mouse anti-human RV VP7 monoclonal antibody exhibited good neutralization activity, with a cell protection rate of $43.3 \%$ and a neutralization titer of 1:446.

In the present study, a model of RV infection in young mice was established. Mice were treated with ribavirin, 100 or $50 \mu 1$ monoclonal antibody or a negative control. The results demonstrated that the positive rate of colloidal gold RV detection in mice treated with $100 \mu 1$ monoclonal antibody was significantly lower than that in the negative control group. However, the positive rate of colloidal gold RV detection in ribavirin-treated group was not statistically lower than that of the negative control group, which is inconsistent with a previous report on ribavirin resistance to RV treatment (36). It has been reported that treatment with ribavirin, a broad-spectrum antiviral agent, phosphorylates ribavirin upon entry into virus-infected cells (37). The products then inhibit or reduce viral synthetases, mRNA guanosine transferase, inosine monophosphate dehydrogenase and guanosine triphosphate in cells (38). This affects the synthesis of viral proteins and formation of viral RNA, thereby inhibiting virus replication and proliferation and effectively treating RV-induced intestinal inflammation, alleviating clinical symptoms (39). In the current study, the sample size was small and the selected outcome indicator only included a feces RV antigen test without comparisons of certain clinical symptoms, including stool frequency. The protective effect of 
different preparations was therefore evaluated by further calculations. The protection rate of mice following the intragastric administration of $100 \mu 1$ monoclonal antibodies reached $71.4 \%$, which confirmed that the mouse anti-human RV VP7 monoclonal antibody produced in this study was able to neutralize the virus in mice, thus preventing viral proliferation. In addition, the protection rate of the $100 \mu$ l monoclonal antibody group was $14.3 \%$ higher than that of the ribavirin group.

The present study had several limitations. For instance, the number of mice selected was small and an increased sample size should thus be utilized to confirm the results obtained. In addition, future studies should assess whether the VP7 monoclonal antibody can be directly inoculated into an individual to provide immuno-protection. Furthermore, it is unclear whether the VP7 monoclonal antibody should only be used for the in vitro screening of anti-viral drugs. The efficacy of the VP7 monoclonal antibody has also not been compared with other vaccines that are currently in use, which will be investigated further in future studies.

In conclusion, mouse anti-human RV VP7 monoclonal antibodies can be successfully generated using the ascites method. These monoclonal antibodies demonstrate a good neutralization effect on the Wa strain human $\mathrm{RV}$ in vitro and in vivo. A higher dose was associated with a greater protective effect and the protective effects of high doses were superior to that of ribavirin.

\section{Acknowledgements}

Not applicable.

\section{Funding}

No funding was received.

\section{Availability of data and materials}

The datasets used and/or analyzed during the present study are available from the corresponding author on reasonable request.

\section{Authors' contributions}

MZ, JY, LZ, HW, XP, ZD, YY and WL collected and interpreted the data. MZ and YY drafted the manuscript. MZ and WL revised it critically for important intellectual content. BW and ML were responsible for the conception and design of the study. All authors read and approved the final manuscript.

\section{Ethics approval and consent to participate}

The study was approved by the Committee on Animal Research and Ethics of West China School of Basic Medical Sciences and Forensic Medicine, Sichuan University (Chengdu, China).

\section{Patient consent for publication}

Not applicable.

\section{Competing interests}

The authors declare that they have no competing interests.

\section{References}

1. Yin N, Yang FM, Qiao HT, Zhou Y, Duan SQ, Lin XC, Wu JY, Xie YP, HeZL, Sun MS and Li HJ: Neonatal rhesus monkeys as an animal model for rotavirus infection. World J Gastroenterol 24: 5109-5119, 2018.

2. Layton JB, Butler AM, Panozzo CA and Brookhart MA: Rotavirus vaccination and short-term risk of adverse events in US infants. Paediatr Perinat Epidemiol 32: 448-457, 2018.

3. Vannie P, Capua I, Le Potier MF, Mackay DK, Muylkens B, Parida S, Paton DJ and Thiry E: Marker vaccines and the impact of their use on diagnosis and prophylactic measures. Rev Sci Tech 26: 351-372, 2007.

4. Teng Y, Zhao B, Pan X, Wen Y and Chen Y: A new rotavirus VP6-based foreign epitope presenting vector and immunoreactivity of VP4 epitope chimeric proteins. Viral Immunol 27: 96-104, 2014

5. Perez CA, Eichwald C, Burrone O and Mendoza D: Rotavirus vp7 antigen produced by Lactococcus lactis induces neutralizing antibodies in mice. J Appl Microbiol 99: 1158-1164, 2005.

6. Morozova OV, Sashina TA, Fomina SG and Novikova NA: Comparative characteristics of the VP7 and VP4 antigenic epitopes of the rotaviruses circulating in Russia (Nizhny Novgorod) and the Rotarix and RotaTeq vaccines. Arch Virol 160: 1693-1703, 2015

7. Yang SH: Research on genetic engineering subunit vaccine of A group bovine rotavirus. Chin J Zoonoses 27: 506-510, 2011 (In Chinese).

8. Jalilvand S, Afchangi A, Mohajel N, Roohvand F and Shoja Z: Diversity of VP7 genes of G1 rotaviruses isolated in Iran, 2009-2013. Infect Genet Evol 37: 275-279, 2016.

9. Macek C: Monoclonal antibodies: Key to a revolution in clinical medicine. JAMA 247: 2463-2470, 1982.

10. Peterson NC and Peavey JE: Comparison of in vitro monoclonal antibody production methods with an in vivo ascites production technique. Contemp Top Lab Anim Sci 37: 61-66, 1998.

11. Kairemo KJ, Lappalainen AK, Kääpä E, Laitinen OM, Hyytinen T, Karonen SL and Grönblad M: In vivo detection of intervertebral disk injury using a radiolabeled monoclonal antibody against keratan sulfate. J Nucl Med 42: 476-482, 2001.

12. Ogawa M, Regino CA, Choyke PL and Kobayashi H: In vivo target-specific activatable near-infrared optical labeling of humanized monoclonal antibodies. Mol Cancer Ther 8: 232-239, 2009.

13. Fernández D, Valle I, Llamos R, Guerra M, Sorell L and Gavilondo J: Rapid detection of rotavirus in faeces using a dipstick system with monoclonal antibodies and colloidal gold as marker. J Virol Methods 48: 315-323, 1994.

14. Zhang GM and Yao GH: Investigation on genetic background of Kunming mice (KM mice) in China. Chin J Lab Anim Sci 7: 246-251 (In Chinese).

15. Shang H, Wei H, Yue B, Xu P and Huang H: Microsatellite analysis in two populations of Kunming mice. Lab Anim 43: 34-40, 2009.

16. Ma P, Wu Y, Zeng Q, Gan Y, Chen J, Ye X and Yang X: Oxidative damage induced by chlorpyrifos in the hepatic and renal tissue of Kunming mice and the antioxidant role of vitamin E. Food Chem Toxicol 58: 177-183, 2013.

17. Weng J, Yang L, Lei C, Li T, Peng G, Fu C, Han X, Li H, Jiang Z, Zhang Z, et al: Elimination of mycoplasma contamination from infected human hepatocyte $\mathrm{C} 3 \mathrm{~A}$ cells by intraperitoneal injection in BALB/c mice. Front Cell Infect Microbiol 7: 440, 2017.

18. Tammer R, Evensen O, Lutz $\mathrm{H}$ and Reinacher $\mathrm{M}$ : Immunohistological demonstration of feline infectious peritonitis virus antigen in paraffin-embedded tissues using feline ascites or murine monoclonal antibodies. Vet Immunol Immunopathol 49: 177-82, 1995.

19. Zheng J, Zhang H, Bao K, Gao W, Xu C and Xia C: Preparation of monoclonal antibodies against bovine progesterone. Monoclon Antib Immunodiagn Immunother 34: 275-277, 2015.

20. Ezzatifar F, Majidi J, Baradaran B, Aghebati Maleki L, Abdolalizadeh J and Yousefi M: Large scale generation and characterization of anti-human IgA monoclonal antibody in ascitic fluid of BALB/c mice. Adv Pharm Bull 5: 97-102, 2015.

21. Velez D, Miller L and Macmillan JD: Use of tangential flow filtration in perfusion propagation of hybridoma cells for production of monoclonal antibodies. Biotechnol Bioeng 33: 938-940, 1989. 
22. Rokni M, Razavi AR, Shokri F, Ahmadi Kia K, Solaymani-MohammadiF, Chahardoli R and Saboor-Yaraghi AA: Enhancement of monoclonal antibody production after single and combination treatment of the hybridoma cells with all-trans retinoic acid and docosahexaenoic acid: An in vitro and in vivo study. Int Immunopharmacol, 59: 295-300, 2018.

23. Hnasko R, Lin AV, Stanker L and McGarvey J: A bioassay for optimization of macrophage-conditioned medium as a culture supplement to promote hybridoma cell survival and growth Monoclon Antib Immunodiagn Immunother 37: 126-133, 2018.

24. Yu YC, Huang YC and Lee TY: Purification of antibodies from protein mixtures and mouse ascites fluid using Zeolite $\mathrm{X}$ Biotechnol Prog 14: 332-337, 1998.

25. Ohkawa K, Tsukada Y and Hirai H: Effect of antibody to rat alpha-fetoprotein (AFP) on protein and DNA synthesis of rat ascites hepatoma AH66 cells. Gan To Kagaku Ryoho 11: 227-234, 1984 (In Japanese).

26. Johnson E, Miribel L, Arnaud P and Tsang KY: Purification of IgM monoclonal antibody from murine ascitic fluid by a two-step column chromatography procedure. Immunol Lett 14: 159-165, 1987.

27. Jermy A, Beeson D and Vincent A: Pathogenic autoimmunity to affinity-purified mouse acetylcholine receptor induced without adjuvant in BALB/c mice. Eur J Immunol 23: 973-976, 1993.

28. Yavuz H, Bereli N, Yilmaz F, Armutcu C and Denizli A: Antibody purification from human plasma by metal-chelated affinity membranes. Methods Mol Biol 1286: 43-46, 2015.

29. Graczyk TK and Cranfield MR: Detection of Cryptosporidiumspecific serum immunoglobulins in captive snakes by a polyclonal antibody in the indirect ELISA. Vet Res 28: 131-142, 1997.

30. Pringels L, Broeckx V, Boonen K, Landuyt B and Schoofs L: Abundant plasma protein depletion using ammonium sulfate precipitation and protein A affinity chromatography. J Chromatogr B Analyt Technol Biomed Life Sci 1089: 43-59, 2018.
31. Grodzki AC and Berenstein E: Antibody purification: Ammonium sulfate fractionation or gel filtration. Methods Mol Biol 588: 15-26, 2010.

32. Kent UM: Purification of antibodies using ammonium sulfate fractionation or gel filtration. Methods Mol Biol 34: 13-21, 1994.

33. Ahlstedt S, Holmgren J and Hanson LA: The validity of the ammonium sulphate precipitation technique of estimation of antibody amount and avidity. Immunology 25: 917-922, 1973

34. Surin AM, Sharipov RR, Krasil'nikova IA, Boyarkin DP, Lisina OY, Gorbacheva LR, Avetisyan AV and Pinelis VG: Disruption of functional activity of mitochondria during MTT assay of viability of cultured neurons. Biochemistry (Mosc) 82: 737-749, 2017.

35. Nguyen VS, Shi L, Luan FQ and Wang QA: Synthesis of kaempferide Mannich base derivatives and their antiproliferative activity on three human cancer cell lines. Acta Biochim Pol 62: 547-552, 2015.

36. Shetty AK, Gans HA, So S, Millan MT, Arvin AM and Gutierrez KM: Intravenous ribavirin therapy for adenovirus pneumonia. Pediatr Pulmonol 29: 69-73, 2000.

37. Gross AE and Bryson ML: Oral ribavirin for the treatment of noninfluenza respiratory viral infections: A systematic review. Ann Pharmacother 49: 1125-1135, 2015

38. Satoh S, Mori K, Onomura D, Ueda Y, Dansako H, Honda M, Kaneko S, Ikeda M and Kato N: Ribavirin suppresses hepatic lipogenesis through inosine monophosphate dehydrogenase inhibition: Involvement of adenosine monophosphate-activated protein kinase-related kinases and retinoid X receptor $\alpha$. Hepatol Commun 1: 550-563, 2017.

39. Musser JMB, Heatley JJ, Koinis AV, Suchodolskin PF, Guo J, Escandon P and Tizard IR: Ribavirin inhibits parrot bornavirus 4 replication in cell culture. PLoS One 10: e0134080, 2015. 